\title{
Precauciones en la atención de pacientes hospitalizados por influenza aviar $\mathrm{H} 5 \mathrm{~N} 1$
}

\author{
Alberto Fica C., Marcela Cifuentes D., M. Cristina Ajenjo H., Luis Delpiano M., Naldy Febre V., \\ Wilma Medina L. y Yolanda Parada E., en representación del \\ Comité Consultivo de Infecciones Intrahospitalarias, Sociedad Chilena de Infectología
}

Recibido: 1 agosto 2006 Aceptado: 11 agosto 2006

Correspondencia a: Alberto Fica Cubillos sochinf@sochinf.cl

\section{Precautions in attending avian influenza H5N1 inpatients}

Several agencies have proposed infection control guidelines for management of patients admitted with the diagnosis of avian influenza. These guidelines aim to prevent transmission from the patient to hospital personnel and other inpatients. The guidelines presented here by the Advisory Committee of Nosocomial Infections have been elaborated for the local medical communitty after reviewing currently available recommendations. Key recommendations include admission to an isolation ward, cohorting of confirmed cases, hand hygiene with antiseptic solutions, use of N95 type masks, non-sterile disposable gloves and eye protection equipment during examination or when performing aerosols-generating procedures. Use of patient-exclussive clinical instruments, daily disinfection of the hospital ward, implementation of measures to reduce risk of needle stick injuries and eye splashing, and reinforcement of appropriate sampling and transport of blood and other corporal fluids, are also recommended.

Key words: Avian influenza; Nosocomial infection; Prevention; Guidelines.

Palabras claves: Influenza aviar; Infección nosocomial; Prevención; Guías.

\section{Antecedentes}

$\mathrm{L}$

a epizootia de influenza aviar ha motivado el diseño de planes de contingencia por diferentes organismos de salud en el mundo, entre otros la Organización Mundial de la Salud (OMS) ${ }^{1}$, la Organización Panamericana de la Salud (OPS)2 , el Centers for Disease Control and Prevention (CDC) de Estados Unidos $^{3}$, la Agencia de Protección de Salud en el Reino Unido ${ }^{4}$ y el Sistema de Salud Canadiense ${ }^{5}$. En Chile, el Ministerio de Salud (MINSAL) también ha indicado medidas de contingencia para esta situación ${ }^{6}$.

Estos planes abarcan diferentes áreas de trabajo y una de ellas han sido las precauciones que deben adoptar las instituciones y el personal de salud para la atención de pacientes confirmados o sospechosos de tener esta enfermedad durante su estadía hospitalaria.

Hasta el momento la epizootia de influenza aviar por el virus $\mathrm{A} / \mathrm{H} 5 \mathrm{~N} 1$ ha afectado ocasionalmente al Hombre, aunque con una alta tasa de letalidad, superior al $30 \%$, y llegando en ocasiones a $80 \%^{7-9}$.

La afinidad de la hemaglutinina viral, glicoproteína (y antígeno) de superficie, por residuos de ácido siálico, explica en parte la especificidad de hospedero que caracteriza a los diferentes subtipos del virus A. Los virus que atacan a la especie humana se unen preferentemente a residuos de ácido siálico unidos a galactosa por un enlace $\alpha-2,6$, presentes en forma predominante en las células epiteliales del tracto respiratorio del Hombre, mientras que los virus que atacan a las aves tienden a unirse preferentemente a moléculas de ácido siálico-galactosa con enlaces $\alpha-2,3$, los que abundan en el epitelio intestinal de las aves ${ }^{8}$. Esta especificidad explica la dificultad de un determinado virus influenza en atravesar hacia otras especies. Sin embargo, en los epitelios de cerdos y pollos están presentes tanto las conformaciones $\alpha-2,6$ como las $\alpha-2,3$, facilitando coinfecciones y reordenamientos genéticos que se traducen en la emergencia de nuevas variantes.

El virus influenza A H5N1 no tiene la capacidad de unirse eficientemente a los receptores presentes en la mucosa nasal, paranasal, faríngea, traqueal o bronquial; las células epiteliales tienen en estos sitios receptores de ácido siálico unidos a galactosa con una conformación $\alpha-2,6$, impidiendo la adsorción y repli- 
cación viral in situ ${ }^{10}$. En cambio, se une preferentemente a células con receptores de especificidad $\alpha-2,3$, presentes en los niveles más bajo del árbol respiratorio (neumocitos tipo II y células epiteliales de bronquiolos y alvéolos), permitiendo en este lugar su replicación y el consecuente daño tisular y desarrollo de neumonía ${ }^{10}$. Este tipo de receptores también está presente en la conjuntiva, tejido que podría participar en la transmisión del virus influenza aviar H5N1. ${ }^{11}$

En pacientes que son internados con influenza aviar por $\mathrm{H} 5 \mathrm{~N} 1$ se justifica adoptar medidas de precaución por el riesgo de contagiar al personal de salud y de generar brotes nosocomiales que pudieran afectar a otros pacientes.

A diferencia del virus influenza A que afecta al Hombre y que se caracteriza por su alta contagiosidad, el tipo viral $\mathrm{H} 5 \mathrm{~N} 1$ no se ha propagado en forma sostenida entre los humanos; las medidas de precaución han sido elaboradas considerando el riesgo potencial de emergencia de variantes de fácil propagación, o la propagación ocasional hacia otros seres humanos. La transmisión ocasional y no sostenida del virus influenza A H5N1 entre seres humanos, ha sido documentada entre contactos familiares de un paciente índice, sin haber estado expuestos a aves ${ }^{12,13}$. También ha sido establecida la diseminación interhumanos en el personal de salud, mediante estudios caso-control con pruebas serológicas, que comprobaron una mayor seroprevalencia en aquel personal que atendió pacientes con influenza aviar que en personal que no los atendió, luego de haberse controlado debidamente factores confundentes como la exposición domiciliaria a aves ${ }^{14}$. Sin embargo, otras experiencias no han encontrado evidencias de transmisión hacia el personal de salud, ya sea si aquellos que atendieron directamente a los pacientes afectados utilizaron o no barreras protectoras ${ }^{15,16}$.

La infección humana por el virus influenza H5N1 ha tenido un período de incubación habitual de 2 a 4 días, extendiéndose en algunos casos, a 8 días?

La transmisión del virus influenza H5N1 entre seres humanos puede teóricamente ocurrir por alguna de las siguientes vías: gotitas, contacto y aerosoles, sin descartarse una transmisión entérica asociada a las manifestaciones predominantemente digestivas observada en algunos pacientes ${ }^{16}$. La transmisión mediante gotitas es la forma de propagación más rápida del virus influenza; por su densidad y tamaño, las gotitas no permanecen suspendidas en el aire. En la transmisión participan también las secreciones respiratorias de pacientes que contaminan las manos o pañuelos de personas susceptibles y transfieren este inóculo a sus respectivas mucosas respiratorias ${ }^{7}$. Se reconoce actualmente que los mecanismos de transmisión más relevantes corresponden a gotitas y secreciones emanadas del paciente.

Atendiendo a estos mecanismos, el espaciamiento entre pacientes a más de un metro de distancia, el uso de mascarillas convencionales al aproximarse al paciente y la protección mediante barreras adicionales como gafas o delantales en caso de preverse salpicaduras, aparecen como medidas suficientes para enfrentar este tipo de pacientes. Así, se han diseñado las precauciones convencionales de aislamiento ante pacientes que se hospitalizan con influenza humana o sospecha de ella.

Sin embargo, en el caso de influenza aviar, varios factores adicionales han llevado a modificar este enfoque, sugiriendo un nivel de protección más agresivo. Estos factores incluyen: la alta letalidad que ha tenido hasta ahora la influenza aviar en la especia humana, la transmisión documentada, aunque infrecuente, de este agente viral entre seres humanos, la ausencia de tratamientos de eficacia demostrada, la emergencia de resistencia durante el tratamiento antiviral, la no disponibilidad de vacunas en el corto plazo y la documentación clara de nuevas pandemias por variantes virales de origen animal en el último siglo ${ }^{8,9,12,17,18}$.

Por otra parte, se ha podido documentar la participación de aerosoles en una fracción de los brotes de influenza, especialmente en espacios cerrados ${ }^{19,20} \mathrm{y}$ ello implica medidas adicionales a las precauciones recomendadas para evitar la transmisión por gotitas. En la práctica hospitalaria existen numerosos procedimientos que generan aerosoles y que deben ser aplicados en pacientes con patología respiratoria: intubación endotraqueal, aspiración de secreciones, nebulizaciones y fibrobroncoscopia. Además sobre $60 \%$ de estos pacientes requerirán atención en UCI y procedimientos de este tipo ${ }^{8,9}$.

La posible participación de aerosoles en la transmisión de influenza es relevante como problema de control de infecciones debido a la necesidad de incorporar el manejo del aire y barreras eficientes para evitar la inhalación de estas partículas de muy pequeño tamaño. Además, la dosis infectante requerida con aerosoles es mucho más baja que la requerida para la transmisión de influenza mediante gotitas, asegurando una mayor tasa de ataque. Ante la emergencia de una cepa epidémica, donde no existe inmunidad previa en la población, pequeñas dosis infectantes pueden asegurar el desarrollo de enfermedad, siendo ésta una característica de la transmisión por aerosoles ${ }^{19}$.

Esta situación ha sido asumida por diferentes agencias gubernamentales o globales de salud en el mundo y casi todas sus recomendaciones consideran no sólo la transmisión por gotitas y contacto con secreciones, sino que también por aerosoles pequeños. 


\begin{tabular}{|c|c|c|c|c|c|c|}
\hline Componente & OMS* & CDC* & RU* & Canadá & OPS* & MINSAL* \\
\hline Habitación individual & $+/ \mathrm{COHORTE}$ & + & $+/ \mathrm{COHORTE}$ & + & + & $+/ \mathrm{COHORTE}$ \\
\hline Presión negativa & + & + & & + & + & \\
\hline Filtros HEPA** & & + & & & & \\
\hline Mascarilla N95 & + & + & & En $1^{\text {a }}$ etapa & + & \\
\hline Mascarilla quirúrgica & $\left(2^{a}\right.$ ETAPA $)$ & & + & En $2^{a}$ etapa & & + \\
\hline Gafas & + & + & + & + & + & + \\
\hline Guantes & + & + & + & + & + & + \\
\hline Delantal & + & + & & + & + & + \\
\hline Botas & & & & + & & \\
\hline Prevención de accidentes cortopunzantes & + & & + . & & + & + \\
\hline Precauciones ante nebulizaciones $u$ otras terapias respiratorias & + & & + & & & \\
\hline \multicolumn{7}{|l|}{ Profilaxis antiviral para el personal de salud } \\
\hline \multicolumn{7}{|c|}{$\begin{array}{l}\text { *: OMS: Organización Mundial de la Salud. CDC: Centers for Disease Control and Prevention. RU: Agencia de Protección de Salud del Reino Unido. OPS: } \\
\text { Organización Panamericana de la Salud. MINSAL: Ministerio de Salud de Chile } \\
\text { **: High Efficiency Particle Arresting: filtros de alta eficiencia } \\
\text { Nota: los espacios en blanco indican que no hay recomendaciones específicas al respecto. }\end{array}$} \\
\hline
\end{tabular}

Desafortunadamente, las mascarillas quirúrgicas no son efectivas para impedir la inhalación de aerosoles, y la superposición de varias mascarillas quirúrgicas no aumenta la eficiencia de esta filtración ${ }^{21}$. En cambio, las mascarillas tipo N95 tienen una alta eficiencia de filtración y permiten retener partículas de tamaño muy pequeño, tales como agentes virales y el bacilo de Koch.

Las recomendaciones actuales del MINSAL de Chile no incluyen o consideran las precauciones por aerosoles ${ }^{6}$.

Otro aspecto a considerar es que los pacientes con influenza aviar, a diferencia de lo que sucede durante la influenza humana, han presentado viremia, la que podría explicar el compromiso gastrointestinal y encefálico descrito en algunos pacientes. La existencia de viremia en casos de influenza aviar H5N1 tiene importantes implicancias en el manejo y prevención de accidentes cortopunzantes durante la asistencia de estos pacientes, incluyendo la recolección de exámenes, la manipulación de las muestras en el laboratorio, y durante el procesamiento de las muestras respiratorias, lo que requiere de un laboratorio de nivel de bioseguridad tipo III $^{22}$.

El virus de influenza aviar es inactivado con desinfectantes de uso habitual como hipoclorito de sodio al $1 \%$ y alcohol al $70 \%{ }^{23}$.

\section{Precauciones sugeridas por diferentes organismos}

Las precauciones aplicadas o sugeridas consideran mayoritariamente un conjunto de medidas que mez- clan componentes de precauciones por aerosoles, por gotitas y de contacto (Tabla 1).

Las recomendaciones difieren en cuanto al uso de salas con presión negativa, uso de filtros de alta eficiencia (HEPA: High Efficiency Particle Arresting) tipo de mascarillas, precauciones sobre la generación de aerosoles, prevención de accidentes cortopunzantes, gorros y cubre- calzado. No obstante, existen varios elementos comunes en estas recomendaciones (Tabla 2) y su disparidad se explica porque estas guías se han construido con datos inciertos.

Tabla 2. Elementos comunes contenidos en la mayor parte de las recomendaciones

internacionales para el control nosocomial de influenza aviar A/H5N1

Paciente

- Hospitalización en habitación individual o en cohorte con casos confirmados

Personal

- Lavado de manos

- Mascarilla N95

- Protección ocular con gafas ad-hoc al acercarse al paciente si se anticipan salpicaduras

- Guantes

- Delantal 


\section{Análisis de recomendaciones específicas}

Tipo de habitación. Todas las recomendaciones sugieren uso de aislamiento individual y la agrupación de pacientes, una vez confirmada la infección, en cohortes. Debe tenerse presente que si se plantea que uno de los mecanismos de transmisión potencial corresponde a aerosoles, será fundamental la hospitalización en una sala individual debido a que todo el aire de la pieza se contamina y cualquier persona que sea hospitalizada en el mismo lugar puede contagiarse. En contraste, para enfermedades transmitidas por gotitas, no existe una contaminación del aire de la habitación ya que las gotitas no permanecen en suspensión y por ende, se puede compartir la pieza con otras condiciones siempre y cuando se respete el mencionado espaciamiento mínimo.

Idealmente, estas habitaciones deben tener un manejo de presiones de aire y de purificación, de las que en nuestro medio se dispone excepcionalmente. La presión de la sala debe ser negativa respecto al pasillo o corredor para impedir la salida de microorganismos y debe incluir filtros de aire tipo HEPA para el tratamiento del aire contaminado. Existen actualmente en el mercado unidades HEPA portátiles eléctricas, que podrían ser consideradas en piezas individuales, equipos que no han sido evaluados en epidemias de influenza.

Barreras protectoras. El uso de mascarillas, guantes, delantales y gafas en el personal que atiende al paciente tiene por objeto evitar el contagio por los diferentes mecanismos de transmisión involucrados en la influenza aviar; impiden el contacto con secreciones, la inhalación de gotitas o aerosoles y salpicaduras sobre mucosas.

Tipo de mascarillas. Como se puede apreciar, la recomendación oficial del MINSAL en Chile presenta sólo dos diferencias importantes respecto a las guías de otras elaboradas por otros organismos, relativas a la necesidad de salas con presión negativa y al uso de la mascarilla tipo N95 en el personal de salud. La primera de estas exigencias se entiende porque nuestro medio no puede proveer por un déficit de infraestructura, salas con presión negativa en forma universal en el corto o mediano plazo. La recomendación de una mascarilla quirúrgica en lugar de una de tipo N95 es una opción epidemiológica que sólo ha sido adoptada por el Reino Unido pero no por la OMS, la OPS, el CDC $\mathrm{u}$ otras instancias. No obstante, la recomendación del Reino Unido incluye mascarillas tipo N95 en caso de procedimientos que generen aerosoles. Este Comité Consultivo recomienda el uso preferente de mascarillas

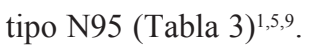

La reutilización de mascarillas NP95 es un tema controversial recientemente revisado por expertos. No se recomienda esta práctica ya que no hay métodos de descontaminación descritos y estos podrían afectar la integridad del material. Sólo en caso de necesidad extrema y escasez de recursos, se podría reutilizar la propia mascarilla usando un protector externo como mascarilla quirúrgica para evitar su contaminación en la superficie externa, incluyendo una cuidadosa manipulación con lavado de manos, antes y después de ser retirada ${ }^{24}$.

No se sugiere el uso de mascarillas para el paciente, podría no tolerarla y/o requerir oxígenoterapia; por otra parte, el paciente debe recibir instrucciones para cubrir su boca y nariz con una toalla desechable cada vez que tosa o estornude. En caso de requerir traslado para efectuarle exámenes o procedimientos, se le debe aplicar una mascarilla tipo N95 o, en su defecto, una de tipo quirúrgica.

Profilaxis antiviral. No existe información disponible sobre la eficacia protectora de esta estrategia en los contactos familiares de pacientes con influenza aviar H5N1 o en el personal de salud que es expuesto a estos casos. Sin embargo, debido a la alta letalidad de esta infección y la ausencia de otras medidas eficaces, se recomienda la administración de un inhibidor de neuraminidasa -oseltamivir- en dosis de $75 \mathrm{mg}$ al día durante 7 a 10 días, en el personal expuesto no protegido 7 .

La eficacia de esta medida en los contactos familiares de pacientes con influenza humana (no aviar) ha variado entre 58 y $89 \%{ }^{25,26}$. Su eficacia en infecciones por influenza A (H5N1) es desconocida y podría estar limitada por la emergencia de virus resistentes a los inhibidores de neuraminidasa, lo que ha sido descrito ya en pacientes tratados por esta condición ${ }^{18}$.

Amantadina o rimantadina no se consideran opciones terapéuticas o profilácticas para influenza A H5N1 por la resistencia de los aislados actuales a estos antivirales ${ }^{7,8}$.

Las recomendaciones de las diferentes organizaciones no consideran la profilaxis antiviral de rutina para

\section{Tabla 3. Razones para optar por mascarillas tipo N95 en la atención} de pacientes con influenza aviar o sospecha de ella

- Necesidad de maximizar las medidas de precaución ante una enfermedad de alta letalidad, sin un tratamiento eficaz conocido, y sin vacunas disponibles

- En la mayor parte de los casos el manejo de estos pacientes requiere hospitalización en unidades intensivas y la aplicación de procedimientos médicos que generan aerosoles

- Aunque no es el mecanismo más importante, la transmisión por aerosoles ha sido documentada para el virus A de influenza humana, en espacios cerrados

- A diferencias de las mascarillas del tipo N95, las mascarillas quirúrgicas no son eficientes para retener material de tamaño muy pequeño 
el personal de salud. Sin embargo, este Comité Consultivo considera necesario aplicarla si el personal participó en la atención del paciente sin haber utilizado medidas protectoras, o si se ha expuesto a un accidente de riesgo biológico.

Vacuna anti-influenza. No existe una vacuna antigripal H5N1 actualmente. Sin embargo, se recomienda vacunar al personal de salud contra la influenza humana en forma anual para evitar el riesgo de coinfección virus humano-virus aviar y la emergencia de variantes virales adaptadas al ser humano.

Manejo de desechos. Los desechos clínicos que contienen fluidos corporales o sangre deben ser manejados con precauciones estándares, utilizando guantes en su manipulación y colocándolos en bolsas resistentes que impidan filtraciones. Las manos deben ser lavadas antes y después de su manipulación. Para reducir los riesgos de contaminación, se recomienda colocar la bolsa retirada en una segunda bolsa antes de su transporte al sitio de acopio, sellarla o anudarla. Las regulaciones vigentes en Chile establecen que las bolsas de desechos de los laboratorios de microbiología deben ser tratadas en autoclave antes de su eliminación, y las de desechos hospitalarios generales deben ser manejadas como basura común y enviadas a relleno sanitario. Los desechos líquidos tales como orina y deposiciones pueden ser vertidos en el sistema de alcantarillado.

Limpieza y desinfección de la sala de hospitalización. Debe efectuarse en forma diaria. Este aseo debe incluir el piso, el mobiliario y las superficies frecuentemente tocadas, tales como manillas, mesas, botones de llamada, baño, teclados de equipos y superficies de ventiladores y bombas de infusión. Se pueden utilizar como desinfectantes: hipoclorito de sodio al $1 \%$, alcohol al $70 \%$ o amonios cuaternarios ${ }^{5}$. Al egreso del paciente se debe efectuar un aseo terminal de la unidad de aislamiento.

Ropa de cama. Su retiro debe ser efectuado con delantal y guantes, plegando las sábanas en forma cuidadosa y sin sacudirlas. La ropa debe ser puesta en bolsas de transporte. Las manos deben ser lavadas antes y después de su manejo. No se requiere de procedimientos especiales de lavado o desinfección.

Vajilla. No requiere procedimientos especiales de lavado o desinfección. El personal de cocina deberá utilizar guantes resistentes al calor cuando se efectúe un lavado manual. No es necesario en ambientes hospitalarios implementar una modalidad de vajilla de uso exclusivo.

Recolección de muestras y transporte al laboratorio. Las personas que participan en la obtención de muestras para el estudio de estos pacientes deben observar las medidas de precauciones estándares y contra infecciones transmitidas por aerosoles. Las muestras deben ser transportadas en sistemas cerrados en forma manual y no por tubos neumáticos. El laboratorio debe ser advertido de la sospecha clínica de influenza aviar y manipular la muestra en una campana de bioseguridad.

\section{Consideraciones finales}

A pesar de que la transmisión de influenza aviar H5N1 entre personas no ocurre frecuentemente, varios reportes dan cuenta de que ello ha ocurrido, afectando a familiares o al personal de salud, aunque hasta la fecha sin consecuencias fatales para este último grupo $^{14,15}$. La transmisión al personal de salud ha sido detectada en situaciones donde no se han aplicado barreras protectoras o ellas han sido instituidas tardíamente. Por lo contrario, en algunos reportes la ausencia de transmisión ha estado asociada al cumplimiento, con un alto porcentaje, de medidas protectoras por parte del personal ${ }^{15}$. Debe tenerse en consideración que los contactos de un caso índice se exponen a contraer una enfermedad con alta letalidad y cuya quimioprofilaxis es de eficacia incierta.

Es éticamente difícil aceptar el desarrollo de estudios comparando la eficacia protectora de mascarillas quirúrgicas versus mascarillas tipo N95. En la transmisión de influenza pueden participar también los aerosoles y ello ha sido sugerido en algunos brotes en espacios cerrados ${ }^{19,20}$. La mascarilla quirúrgica no ofrece protección contra este tipo de transmisión.

Países con un menor PGB que Chile, como Vietnam, han estando aplicando sistemáticamente estas estrategias, siguiendo las recomendaciones internacionales, sin haberse observado casos secundarios en el personal de salud ${ }^{15}$. Más aún, gran parte de estas medidas se han estado implementando en aquellos países afectados por esta infección tales como Indonesia y Vietnam ${ }^{27}$.

El Comité Consultivo de Infecciones Intrahospitalarias de la Sociedad Chilena de Infectología apoya las recomendaciones del MINSAL para el manejo de pacientes con sospecha de gripe aviar y sugiere agregar específicamente el uso de mascarillas tipo N95 en el personal de salud tal como ha sido incluido en guías mundiales y regionales elaboradas por la OMS y la OPS.

Concordamos con la recomendación canadiense de aplicar mascarillas N95 en las etapas iniciales de una epidemia y mascarillas quirúrgicas en caso de escasear los insumos durante una pandemia descontrolada.

El resumen de las recomendaciones de este Comité Consultivo se señala en la Tabla 4. 
Lugar de hospitalización

Habitación individual o implementar aislamiento en cohorte de los pacientes con diagnóstico confirmado

Si existe disponibilidad, aislar en sala con presión de aire negativa

Precauciones estándares

Lavado de manos con jabón antiséptico o alcohol-gel antes de la atención del paciente o antes de manipular material o superficies potencialmente contaminadas con secreciones respiratorias o fluidos corporales. Uso de guantes de procedimiento, cada vez que se tenga contacto con el paciente, fluidos corporales o ropa

Precauciones de contacto

Guantes de procedimientos antes de tomar contacto con el paciente o su entorno, incluyendo la ropa de cama

Delantal de un solo uso (desechable o de género lavable)

Instrumental clínico de uso exclusivo para el paciente: termómetro, fonendoscopio con desinfección después de su uso, esfigmomanómetro, etc

Precauciones por gotitas $y$ aerosoles

Uso de mascarilla N95 por parte del personal debiendo ser colocada antes de entrar a la pieza y retirada después de su salida

Uso de mascarilla quirúrgica sólo si no existe disponibilidad de mascarillas N95. Éstas deben ser cambiadas cada vez que se encuentren humedecidas y no deben ser reutilizadas

Uso de gafas protectoras al acercarse al paciente a menos de un metro de distancia

Instrucciones al paciente

Instruirlo para cubrir su boca y nariz cuando estornude o tosa, utilizando pañuelos desechables. Eliminar estos pañuelos o toallas en una bolsa o recipiente al lado del paciente.

Traslado del paciente

Disminuir a un mínimo la salida del paciente de su habitación Uso de mascarilla N95 al abandonar la pieza. Instruir al paciente sobre la necesidad de cubrir su boca y nariz al toser y/o estornudar. En caso de falencia crítica de mascarillas N95, aplicar en segunda instancia mascarillas quirúrgicas.

Duración de las precauciones

En niños hasta 12 años: hasta 14 días post desaparición de la fiebre. Sobre 12 años de edad: hasta 7 días post desaparición de la fiebre

Terapia respiratoria

Instruir al personal para tomar precauciones estándares, incluyendo uso de mascarillas N95 y gafas, lavado de manos y guantes de procedimiento cada vez que se efectúe alguno de los siguientes procedimientos: nebulizaciones, obtención de muestra de expectoración, aspiración de secreciones de la vía aérea, intubación endotraqueal, ventilación no invasora con presión positiva, fibrobroncoscopia. Los procedimientos que generan aerosoles idealmente deben ser realizados en salas con presión de aire negativa

Profilaxis antiviral en el personal de salud

Indicada sólo en quienes participaron en la atención de un paciente sin haber usado medidas protectoras o si ha ocurrido un accidente de riesgo biológico. En ese personal debe vigilarse la temperatura y aparición de síntomas respiratorios por una semana desde el último contacto con un caso confirmado

Vacuna anti-influenza

El personal deben vacunarse anualmente contra la influenza para aminorar el riesgo de una coinfección con H5N1 y la emergencia de variantes virales

Manejo de los desechos microbiológicos

El material de desecho de los laboratorios de microbiología debe ser tratado en autoclaves, en bolsas especiales, antes de su retiro.

Obtención de muestras, transporte, y manipulación en el laboratorio

Durante su obtención deben aplicarse precauciones estándares y por aerosoles. El transporte será efectuado en un sistema cerrado, en forma manual, evitando el uso de sistemas de tubos neumáticos. Debe advertirse al laboratorio de la sospecha clínica de influenza aviar. Las muestras sospechosas de contener virus influenza aviar deben ser manipuladas en una campana de bioseguridad

Manejo de los desechos clínicos

Los desechos clínicos deben ser tratados con precauciones estándares (guantes + lavado de manos), colocándolos en bolsas resistentes que impidan filtraciones. Los desechos líquidos, tales como orina y deposiciones, pueden ser vertidos en el sistema de alcantarillado

Aseo y desinfección de la unidad de aislamiento

Limpieza y desinfección diaria de la habitación. Incluir piso, mobiliario, manillas, mesas, botones de llamada, baño, teclados y superficies de los equipos médicos. Se pueden utilizar diferentes desinfectantes. Debe efectuarse aseo terminal al egreso del paciente

Ropa de cama

El funcionario que retire la ropa de cama debe protegerse con delantal y guantes, evitará sacudirlas y deberá colocarla en bolsas de transporte. Lavado de manos antes y después de su manejo

Vajilla

No se requieren procedimientos especiales de lavado. El personal de cocina debe usar guantes resistentes al calor si se utiliza un sistema de lavado manual

Visitas de familiares

Deben ser restringidas a un mínimo prudente, indicándoseles uso de mascarilla N95, lavado de manos y guantes de procedimiento en ellos 


\section{Resumen}

Diferentes agencias han propuesto guías para el control de infecciones por influenza aviar durante la atención de los pacientes afectados, con el objeto de disminuir el riesgo de transmisión cruzada hacia otros pacientes y hacia al personal de salud. La guía elaborada por este comité recoge las diferentes recomendaciones y entrega una propuesta adaptada a nuestro medio. Forman parte central de ellas, la hospitalización en pieza individual y la cohorte de pacientes, el uso de mascarillas tipo N95 (de alta eficiencia), la aplicación de prácticas de higiene de manos en el personal, guantes de procedimientos desechables y el uso de gafas protectoras al acercarse al paciente o cuando se generan aerosoles. Las precauciones requieren también la minimización de accidentes cortopunzantes y la toma de exámenes y su transporte adecuado al laboratorio.
A pesar de que no se ha documentado una transmisión por aerosoles para influenza aviar, y que su principal mecanismo de transmisión ocurre por gotas y secreciones, se considera prudente aplicar precauciones para transmisión por aerosoles debido a la elevada letalidad de esta enfermedad, a la ausencia de vacunas protectoras disponibles actualmente, a la eficacia incierta de la terapia antiviral y a la transmisión por aerosoles documentada para influenza humana en espacios cerrados.

\section{Agradecimientos}

A Leonor Jofré $\mathrm{M}$, integrante del Comité Consultivo de Enfermedades Emergentes de la Sociedad Chilena de Infectología, por la excelente revisión crítica de este manuscrito.

\section{Referencias}

1.- Avian influenza, including influenza A (H5N1), in humans: WHO interim infection control guideline for health care facilities. www.who.int/csr/disease/avian influenza/ guidelines/infectioncontrol1/en/ index.html (accedido julio 2006).

2.- PAHO. PAHO strategic and operational plan for responding to pandemic influenza. 2005. www.paho.org/english/ad/dpc/cd/flupan.htm

3.- CDC. Interim recommendations for infection control in health-care facilities caring for patients with known or suspected avian influenza. http://www.cdc.gov/flu/ avian/pdf/infectcontrol.pdf (accedido marzo 2006).

4.- UK Health Protection Agency. Infection control in hospitals and primary care settings. http:/www.dh.gov.uk/assetRoot/04/12/17/ 54/04121754.pdf (accedido julio 2006).

5.- Public Health Agency of Canada. Human health issues related to domestic avian influenza outbreaks. Canadian Pandemic Influenza Committee and affiliated working groups. http://www.phac-aspc.gc.ca/publicat/ daio-enia/index.html (accedido julio 2006)

6.- Minsal, Chile. Anexo 8. Control de Infecciones. En: Plan de enfrentamiento de pandemia de influenza, Chile 2005. http:// epi.minsal.cl/webInfluenza/frame4.html (accedido marzo 2006).

7.- The Writing Committee of the World Health Organization (WHO) Consultation on Human Influenza A/H5. Avian influenza A (H5N1) infection in humans. N Engl J Med 2005; 353: 1374-85.

8.- Wong S S Y, Yuen K W. Avian influenza virus infections in humans. Chest 2006; 129: 156-68.

9.- Gruber P C, Gomersall C D, Joynt G M. Avian influenza (H5N1): implications for intensive care. Intensive Care Med 2006; 32: $823-9$
10.- Shinya K, Ebina M, Yamada S, Ono M, Kasai $\mathrm{N}$, Kawaoka Y. Influenza virus receptors in the human airway. Nature 2006; 440: 435-6.

11.- Oloffson S. Avian influenza and sialic acid receptors: more than meets the eye? Lancet Infect Dis 2005; 5: 1894-98.

12. - Ungchusak K, Auerwarakulm P, Dowell S F, Kitphati R, Auwanit W, Puthavathana P, et al. Probable person-to-person transmission of avian influenza (H5N1). N Engl J Med 2005; 352: 333-40.

13. - News. Family tragedy spotlights flu mutations. Nature 2006; 442: 114-5.

14.- Buxton Bridges C, Katz J M, Seto WH, Chan P K S, Tsang D, Ho W, et al. Risk of influenza A (H5N1) infection among health care workers exposed to patients with influenza A (H5N1), Hong Kong. J Infect Dis 2000; 181: 344-8.

15.- Liem N T. WHO International Avian Influenza Investigation Team, Vietnam, Lim W. Lack of H5N1 avian influenza transmission to hospital employees, Hanoi, 2004. Emerg Infect Dis 2005; 11: 210-5.

16.- Apisarnthanarak A, Kitphati R Thongphubeth K, Patoomanunt P, Anthanont P, Auwanit W, et al. Atypical avian influenza (H5N1). Emerg Infect Dis 2004; 10: 1321-4.

17.- Tumpey T M, Basler C F, Aguilar P V, Zeng H, Solórzano A, Swayne D E, et al. Characterization of the reconstructed 1918 spanish influenza pandemic virus. Science 2005; 310: 77-80.

18.- De Jong M D, Tan Thanh T, Huu Khanh T, Minh Hien V, Smith G J D, Vinh Chau N, et al. Oseltamivir resistance during treatment of influenza A (H5N1) infection. N Engl J Med 2005; 353: 2667-72.

19.- Buxton Bridges C, Kuehnert MJ, Hall CB. Transmission of influenza: implications for control in health care settings. Clin Infect Dis 2003; 37: 1094-101.

20.- Moser M R, Bender T R, Margolis H S, Noble G R, Kendal A P, Ritter D G.
An outbreak of influenza aboard a commercial airline. Am J Epidemiol 1979; 110: 1-6

21.- Derrick J L, Gomersall C D. Protecting healthcare staff from severe acute respiratory syndrome: filtration capacity of multiple surgical masks. J Hosp Infect 2005; 59: 365-8.

22.- Chutinimitkul S, Bhattarakasol P, Srisuratanon S, Eiamudomkan A,

Kongsomboon K, Damrongwatahapokis S,et al. H5N1 influenza A virus and infected human plasma. Emerg Infect Dis 2006; 12: 1041-3.

23.- Suarez D L, Spackman E, Senne D A, Bulaga L, Welsch AC, Froberg K. The effect of various disinfectants on detection of avian influenza virus by real time RT-PCR. Avian Dis 2003; 47: 1091-5.

24.- Committee on the Development of reusable facemasks for use during an influenza pandemic. Reusability of facemasks during an influenza pandemic. The National Academies Press, Washington, DC. 2006. p1-10. http://www.nap.edu/openbook/ 0309101824/html/index.html (Accedido julio 2006).

25.- Welliver R, Monto A S, Carewicz O, Schatteman E, Hassman M, Hedrick J, et al. Effectiveness of oseltamivir in preventing influenza in households contacts. A randomized controlled trial. JAMA 2001; 285: 748-54

26.- Hayden F G, Belshe R, Villanueva C, Lanno R, Hughes C, Small I, et al. Management of influenza in households: A prospective, randomized comparison of oseltamivir treatment with or without postexposure prophylaxis. J Infect Dis 2004; 189: 440-9.

27.- Lye D C B, Nguyen D H, Giriputro S, Anekthananon T, Eraksoy H, Tambyah P A. Practical management of avian influenza in humans. Singapore Med J 2006; 47: 471-5. 